А. Н. Хоженоева, В. Л. Цэдашиева. Психолого-педагогическое сопровождение детей с аутизмом в специальной (коррекционной) общеобразовательной школе

Научная статья

УДК 376.4

DOI: 10.18101/2307-3330-2021-2-71-75

\title{
ПСИХОЛОГО-ПЕДАГОГИЧЕСКОЕ СОПРОВОЖДЕНИЕ ДЕТЕЙ С АУТИЗМОМ В СПЕЦИАЛЬНОЙ (КОРРЕКЦИОННОЙ) ОБЩЕОБРАЗОВАТЕЛЬНОЙ ШКОЛЕ
}

\author{
(C) Хоженоева Альбина Николаевна \\ педагог-психолог, \\ Специальная коррекционная общеобразовательная школа-интернат № 3 \\ г. Улан-Удэ \\ Россия, 670034, г. Улан-Удэ, ул. Буйко, 25 \\ albina.hozhenoeva@yandex.ru

\section{(C) Цэдашиева Валентина Лхамадиевна} \\ директор, \\ Специальная коррекционная общеобразовательная школа-интернат № 3 \\ г. Улан-Удэ \\ Россия, 670034, г. Улан-Удэ, ул. Буйко, 25 \\ buico25@yandex.ru
}

\begin{abstract}
Аннотация. В статье рассматривается процесс психолого-педагогического сопровождения детей с аутизмом в специальной (коррекционной) общеобразовательной школе. Представлены сведения по проблеме оказания психолого-педагогической помощи и поддержки, направленной на формирование жизненных компетенций учащихся. Имеется краткое описание содержательных компонентов модели сопровождения детей с расстройствами аутистического спектра (РАC) в школьной среде, где обучаются другие школьники с нарушениями развития. Рассмотрены результаты исследования сенсорной, познавательной и социальной функциональных систем у детей с расстройствами аутистического спектра, на основе которых проведена их типологизация. Сделан вывод об актуальности индивидуального подхода по вопросам обучения каждого ребенка с аутизмом, что включает качественное проведение диагностического этапа с использованием специальных оценочных методик и разработку индивидуальной коррекционно-образовательной программы, способствующей повышению уровня социальной адаптации, развитию и продвижению в овладении жизненными компетенциями.

Ключевые слова: аутизм, расстройства аутистического спектра (РАС), модель
\end{abstract} сопровождения, жизненные компетенции, типологизация детей с РАС.

\section{Для цитирования}

Хоженоева А. Н., Цэдашиева В. Л. Психолого-педагогическое сопровождение детей с аутизмом в специальной (коррекционной) общеобразовательной школе // Вестник Бурятского государственного университета. Образование. Личность. Общество. 2021. № 2. С. 71-75.

Для современного этапа реформирования системы образования характерно создание условий полноценного включения в образовательное пространство детей с ограниченными возможностями здоровья (ОВ3), образование которых определяется Федеральным государственным образовательным стандартом, ак- 
центированным на неоднородности состава детей каждой нозологической категории, и предполагает вариативность содержания образовательных программ, а значит разнообразие видов и объемов необходимой им психологопедагогической помощи [1].

С целью разработки, обоснования и апробирования модели процесса психолого-педагогического сопровождения детей с РАС в условиях коррекционной школы мы провели исследование, предметом которого выступили организационно-содержательные условия психолого-педагогического сопровождения детей с аутизмом в специальной (коррекционной) общеобразовательной школе. Исходная выборка состояла из 11 учащихся начальных классов (1-3-е классы), обучение которых совпало с введением федерального государственного образовательного стандарта общего образования для детей с умственной отсталостью (интеллектуальными нарушениями).

Отсутствие целостного концептуального подхода к психологопедагогическому сопровождению в условиях специальной (коррекционной) школы в связи с неоднородностью развития школьников с аутизмом и недостаточной разработанностью вопросов оказания им специальной помощи и поддержки обусловило необходимость составления функциональной модели сопровождения детей с РАС. В качестве основной цели моделирования процесса сопровождения мы определили организацию системы комплексного взаимодействия педагогов и специалистов школы при создании условий, позволяющих формировать жизненные компетенции учащихся с РАС для успешной их социальной адаптации и интеграции в общество. При этом постарались учесть механизмы реализации поставленной цели, а также ее структуру и основные свойства, чтобы управлять процессом сопровождения и уметь прогнозировать его последствия. Цикличность процесса сопровождения последовательно реализуется через следующие этапы: диагностический, поисково-вариативный, практикодейственный и аналитический. В нашей модели мы выделили управленческий, коррекционно-развивающий, психолого-педагогический модули с соответствующими задачами и функциями, что позволило объединить конкретные совместные действия всех участников образовательного процесса.

Первазивность нарушения и асинхрония в развитии функциональных областей и навыков детей обусловили детальную оценку их основных функциональных сфер, таких как сенсорная, познавательная и социальная, сформированность которых выявляли с помощью апробированных методик: «Вопросник сенсорного профиля» О. Б. Богдашиной, протокол педагогического наблюдения [3], «Лист оценки жизненных компетенций» [2]. На основе показателей оценивания жизненных компетенций нами были выделены уровни развития ребенка с PAC, характеризующие его разные образовательные возможности (от варианта «базовой нормы», «минимальный уровень» и до отсутствия сформированности необходимого навыка - «недостаточный» уровень). Определение уровней сформированности навыков позволило провести типологизацию детей. В соответствии с установленными различиями на сенсорном, когнитивном и социальном уровнях были даны рекомендации и определены направления коррекционной работы с учащимися. Таким образом, мы попытались смоделировать специальные условия, удовлетворяющие особым образовательным потребностям детей с РАС в 
А. Н. Хоженоева, В. Л. Цэдашиева. Психолого-педагогическое сопровождение детей с аутизмом в специальной (коррекционной) общеобразовательной школе

каждой выделенной группе для их продвижения в овладении жизненными компетенциями.

Программа психолого-педагогического сопровождения включала:

- проведение коррекционно-развивающих занятий по программе «Преодоление сенсорных нарушений у детей с аутизмом» в рамках игротерапии, сенсорного развития (индивидуальные, подгрупповые, групповые занятия). Использовались четкое планирование и постепенное формирование стереотипа занятия, обыгрывание упражнений и заданий, подстраивание под интересы ребенка; единый сюжет занятий; применение положительного подкрепления;

- создание особой развивающей среды: приобретение специального оборудования и материалов;

- 57\% педагогов прошли обучение на курсах повышения квалификации и профессиональной переподготовки по актуальным вопросам образования детей с PAC. На базе школы создан Центр комплексной реабилитации и абилитации детей-инвалидов (направление - дети с аутизмом) в рамках Комплексной программы по реабилитации и абилитации детей-инвалидов;

- командная работа педагогов школы реализуется через проведение динамического наблюдения, участие в ППК, совместное обсуждение промежуточных результатов;

- организация клуба для родителей «КРУГ».

Обобщенная оценка результатов обследования по методике Протокол педагогического наблюдения показала наличие тенденции ( $\mathrm{p}=0,1$; приведены оценки, полученные по U-критерию Манна - Уитни) к некоторым положительным различиям сформированности навыков социального поведения и познавательной сферы между контрольным и констатирующим этапами работы ( табл.1).

Распределение по уровням сформированности навыков

Таблий 1 на этапах эмпирического исследования

\begin{tabular}{|l|l|l|l|l|l|l|l|l|}
\hline \multirow{3}{*}{ Уровень } & \multicolumn{4}{|c|}{ Констатирующий } & \multicolumn{4}{c|}{ Контрольный } \\
\cline { 2 - 11 } & $\begin{array}{c}\text { Социальное } \\
\text { поведение }\end{array}$ & \multicolumn{2}{|c|}{$\begin{array}{c}\text { Познавательная } \\
\text { сфера }\end{array}$} & \multicolumn{2}{c|}{$\begin{array}{c}\text { Социальное } \\
\text { поведение }\end{array}$} & \multicolumn{2}{|c|}{$\begin{array}{c}\text { Познавательная } \\
\text { сфера }\end{array}$} \\
\cline { 2 - 11 } & Абс.ч. & Отн.ч. & Абс.ч. & Отн.ч. & Абс.ч. & Отн.ч. & Абс.ч. & Отн.ч. \\
\hline Базовый & 0 & 0 & 0 & 0 & 0 & 0 & 1 & 9,1 \\
\hline Минимальный & 2 & 18,2 & 2 & 18,2 & 4 & 36,3 & 3 & 27,3 \\
\hline Недостаточный & 9 & 81,8 & 9 & 81,8 & 7 & 63,6 & 7 & 63,6 \\
\hline
\end{tabular}

По сформированности социальных навыков и навыков интеграции в школу произошли существенные различия $(\mathrm{p}=0,01)$ между уровнем сформированности исследуемых навыков на контрольном и констатирующем этапах. Наблюдалась положительная динамика, отражающаяся в увеличении количества детей, отнесенных к минимальному уровню и в снижении количества детей с недостаточным уровнем. Отсутствие фиксации базового уровня детей можно объяснить особенностями психического дизонтегенеза при данном нарушении.

Проведенное исследование выявило специфические особенности в формировании необходимых навыков в каждой выделенной группе. Дети 3-й группы 
показали минимальный уровень сформированности навыков. Для успешного продвижения в овладении жизненными компетенциями необходима комплексная организация психолого-педагогического сопровождения с поэтапным включением в образовательное пространство школы. Для детей 4-й группы также характерна позитивная динамика. Несмотря на то, что эту группу составляли дети с легкой умственной отсталостью, она была разнородной по наличию и проявлениям проблемного поведения, по уровню развития когнитивных процессов, эмоционально-волевой сферы и др. Полученные результаты подтвердили положение о том, что уровень развития ребенка с ОВ3 не определяется медицинским диагнозом и зависит не только от характера нарушения, но и от качества обучения и воспитания. У детей 1-й и 2-й групп были более выражены аутистические нарушения, тем не менее они показали продвижение в овладении некоторыми навыками социального поведения или познавательной сферы, например, «выполнение инструкции учителя», «возвращение вещи на свое место», «ожидание своей очереди» и др.

Таким образом, у детей - участников экспериментальной выборки произошло статистически достоверное улучшение результатов по исследуемым показателям функциональных сфер. Наибольшая положительная динамика была получена в развитии познавательной сферы, что свидетельствует об эффективности программы обучения. Наименьшую динамику в развитии социальной сферы можно объяснить тем, что формирование социальных навыков предполагает более сложное качественное изменение поведения ребенка с аутизмом, регулируемого новыми аффективными смыслами. Отметим, что приобретение детьми с РАС самостоятельно выполняемых некоторых навыков способствовало уменьшению аутистических проявлений в поведении.

Результаты исследования показывают актуальность индивидуального подхода по вопросам обучения каждого ребенка с аутизмом, что включает качественное проведение диагностического этапа с использованием специальных оценочных методик и разработку индивидуальной коррекционнообразовательной программы с учетом результатов диагностики его основных функциональных сфер, способствующей повышению уровня социальной адаптации, развитию и продвижению в овладении жизненными компетенциями.

\section{Литература}

1. Развитие образования детей с ОВ3 младшего школьного возраста: целевые ориентиры и стратегические направления / О. С. Никольская, О. И. Кукушкина, Е. Л. Гончарова, О. А. Карабанова // Альманах Института коррекционной педагогики «Развитие образования детей с ограниченными возможностями здоровья: 2020-2030 годы». 2019. № 36. С. 5-17. Текст: непосредственный.

2. Манелис Н. Г., Никитина Ю. В., Феррои Л. М. Сенсорные особенности детей с расстройствами аутистического спектра. Стратегии помощи: методическое пособие / под редакцией А. В. Хаустова, Н. Г. Манелис. Москва: ФРЦ ФГБОУ ВО МГППУ, 2018. 70 с. Текст: непосредственный.

3. Хаустов А. В., Красносельская Е. Л., Хаустова И. М. Дети с расстройствами аутистического спектра. Протокол педагогического обследования // Практика управления ДОУ. 2014. № 1. С. 32-50. Текст: непосредственный. 
А. Н. Хоженоева, В. Л. Цэдашиева. Психолого-педагогическое сопровождение детей с аутизмом в специальной (коррекционной) общеобразовательной школе

Статья поступила в редакиию 05.06.2021; одобрена после рецензирования 05.07.2021; принята к публикаичии 29.11.2021.

\title{
PSYCHOLOGICAL AND PEDAGOGICAL SUPPORT FOR CHILDREN WITH AUTISM IN A SPECIAL (REMEDIAL) SECONDARY GENERAL SCHOOL
}

\author{
Albina N. Khozhenoyeva \\ Educational Psychologist, \\ Special (Remedial) Secondary General School No. 3 \\ 25 Buiko St., Ulan-Ude 670002, Russia \\ albina.hozhenoeva@yandex.ru \\ Valentina L. Tsedashieva \\ Principal, \\ Special (Remedial) Secondary General School No. 3 \\ 25 Buiko St., Ulan-Ude 670002, Russia \\ buico25@yandex.ru
}

Abstract. The article analyzes the process of psychological and pedagogical support for children with autism in a special (remedial) secondary general school. The study focuses on the problem of providing psychological and pedagogical assistance to special children aimed at development of their life competencies. We provide a brief description of the substantial components of the support model for ASD children in school environment, where they study together with children having other developmental disorders. The article presents the results of the study of sensory, cognitive and social functional systems in children with autistic spectrum disorders and the typology of children with ASD based on the current findings. We have concluded that there is a need for the individual approach to teaching each child with autism, which should include a high-quality diagnostic stage with use of special assessment techniques, as well as the development of an individual educational program aimed at increasing the level of social adaptation, mastering essential life skills.

Keywords: autism, autistic spectrum disorders (ASD), support model, life competencies, typology of children with ASD.

\section{For citation}

Khozhenoyeva A. N., Tsedashieva V. L. Psychological and Pedagogical Support for Children with Autism in a Special (Remedial) Secondary General School. Education. Person. Society. 2021; 2: 71-75 (In Russ.).

The article was submitted 05.06.2021; approved after reviewing 05.07.2021; accepted for publication 29.11.2021. 